\title{
Adubação orgânica e águas de diferentes níveis salinos no cultivo do algodoeiro de fibra colorida
}

\section{Organic fertilization and waters of different salin levels in the cultivation of colored fiber cotton}

\author{
Leandro de Pádua Souza ${ }^{1}$, Lauriane Almeida dos Anjos Soares ${ }^{2}$, Geovani Soares de Lima ${ }^{3}$, Reginaldo Gomes Nobre ${ }^{4}$, Hans \\ Raj Gheyi ${ }^{5}$, Anderson Bruno Anacleto de Andrade ${ }^{6}$
}

Resumo: No semiárido a ocorrência de longos períodos de estiagem vem tornado a irrigação uma pratica indispensável para exploração agrícola. Desta forma objetivou-se, com esta pesquisa, avaliar o crescimento e a produção de do algodoeiro cv. BRS Jady irrigado com águas de distintos níveis de salinidades e doses de matéria orgânica. O experimento foi conduzido utilizando-se um Neossolo Regolítico Eutrófico de textura franco arenosa no município de Campina Grande, Paraíba. Adotouse o delineamento experimental de blocos ao acaso, em esquema fatorial 4 x 4, com três repetições, cujos os tratamentos resultaram da combinação de quatro níveis de condutividade elétrica da água (CEa) $\left(1,7 ; 3,4 ; 5,1\right.$ e $\left.6,8 \mathrm{dS} \mathrm{m}^{-1}\right)$ e quatro doses de matéria orgânica $\left(0 ; 2,5 ; 3,5\right.$ e 4,5\% em base do volume do solo). A irrigação com água salina de CE a partir $1,7 \mathrm{dS} \mathrm{m}^{-1}$ afetou negativamente o crescimento e a produção do algodoeiro cv. BRS Jady, provocando reduções no diâmetro de caule, altura de planta, área foliar, fitomassa seca total, massa de algodão em pluma, massa total de sementes e rendimento de fibra. A adubação orgânica com doses crescentes promoveu aumento na altura de plantas, área foliar e massa total de sementes do algodoeiro cv. BRS Jady. Houve interação entre os fatores aguas salinas e doses de matéria orgânica para diâmetro caulinar, fitomassa seca total e massa de algodão em pluma, sendo os maiores valores obtidos na das doses de 3,5 e 4,5\% de matéria orgânica.

Palavras-chave: Gossypium hirsutum L.; Estresse salino; Esterco bovino.

\begin{abstract}
In the semiarid the occurrence of long periods of drought has made irrigation an indispensable practice for agricultural exploration. The objective of this research was to evaluate the growth and yield of cotton cv. BRS Jady irrigated with waters of different levels of salinities and doses of organic matter. The experiment was conducted using a sandy loam texture Eutrophic Neolithic in the municipality of Campina Grande, Paraíba. A randomized complete block design was used in a $4 \times 4$ factorial scheme with three replications, the treatments of which were the result of the combination of four levels of electrical conductivity (Ecw) $\left(1.7,3.4,5.1\right.$ And $\left.6.8 \mathrm{dS} \mathrm{m}^{-1}\right)$ and four doses of organic matter $(0,2.5,3.5$ and $4.5 \%$ on the basis of soil volume). Irrigation with EC saline water from $1.7 \mathrm{dS} \mathrm{m}^{-1}$ negatively affected the growth and yield of cotton cv. BRS Jady, causing reductions in stem diameter, plant height, leaf area, total dry matter, feathered cotton mass, total seed mass and fiber yield. Organic fertilization with increasing doses promoted increase in plant height, leaf area and total seed mass of cotton cv. BRS Jady. There was interaction between saltwater factors and organic matter doses for shoot diameter, total dry matter and cotton mass in feathers, the highest values being obtained in the 3.5 and $4.5 \%$ organic matter doses.
\end{abstract}

Key words: Gossypium hirsutum L., Saline stress, Cattle manure

\footnotetext{
*Autor para correspondência

Recebido para publicação em 11/11/2016; aprovado em 23/02/2017

${ }^{1}$ Doutorando em Engenharia Agrícola, Universidade Federal de Campina Grande - CTRN/UFCG, Campina Grande, PB, Brasil. E-mail engenheiropadua@hotmail.com.

${ }^{2}$ Pós-Doutoranda em Engenharia Agrícola, PDJ/CNPq Universidade Federal de Campina Grande-CTRN/UFCG, Campina Grande, PB, Brasil. E-mail: laurispo.agronomia@gmail.com

3Pós-Doutorando em Engenharia Agrícola, PNPD/CAPES, Universidade Federal de Campina Grande-CTRN/UFCG, Campina Grande, PB, Brasil. E-mail: geovanisoareslima@gmail.com.

${ }^{4}$ Doutor em Engenharia Agrícola, Professor Adjunto, Universidade Federal de Campina Grande - CCTA/UFCG, Pombal, PB, Brasil. E-mail: rgomesnobre@yahoo.com.br

${ }^{5}$ Professor Visitante Sênior Nacional/CAPES, Universidade Federal do Recôncavo da Bahia, Cruz das Almas, BA, Brasil. E-mail: hans@ pq.cnpq.br

${ }^{6}$ Mestrando em Sistemas Agroindustriais, Universidade Federal de Campina Grande, CCTA/UFCG, Pombal, PB, Brasil. E-mail: bdeandrade3@gmail.com.
} 


\section{INTRODUÇÃO}

$\mathrm{O}$ algodoeiro de fibra naturalmente colorida tem grande potencial econômico e social para a região semiárida brasileira, fixando a mão de obra, gerando empregos e fornece matéria-prima para a indústria; ainda, atende o apelo ambiental, uma vez que elimina a fase de tingimento na indústria têxtil, a qual tem lançado grande quantidade de resíduos no ambiente (CARDOSO et al., 2010).

Entretanto nas regiões áridas e semiáridas a ocorrência de longos períodos de estiagem e a irregularidade anual das precipitações vem tornado a irrigação uma pratica indispensável para que as culturas expressem seu máximo potencial produtivo (LIMA et al., 2014). É comum utilização de fontes de água com elevada concentração de sais, sobretudo de sódio, nessa Região a, proporcionando efeitos negativos sobre solos e cultivos (NEVES et al., 2009).

Quando em excesso no solo, os sais podem comprometer a exploração agrícola racional, pois, podem exercer efeitos de natureza osmótica, tóxica e nutricional sobre as plantas, além de promover degradação da estrutura física do solo quando a quantidade de sódio adsorvido em relação aos demais cátions é predominante (TAVARES FILHO et al., 2012). O uso de esterco auxilia ainda na melhoria das propriedades químicas e físicas do solo, atuando no fornecimento de nutrientes às culturas, na estruturação do solo, infiltração, retenção de água e aeração do solo (DIAS et al., 2016).

Diante o exposto, objetivou-se com esta pesquisa avaliar o crescimento e produção do algodoeiro de fibra naturalmente colorida submetidos a níveis crescentes de salinidade da água de irrigação e doses de matéria orgânica.

\section{MATERIAL E MÉTODOS}

O experimento foi desenvolvido em casa de vegetação do Centro de Ciências Tecnologia e Recursos Naturais (CTRN) da Universidade Federal de Campina Grande (UFCG), localizado no município de Campina Grande, Paraíba, nas coordenadas geográficas $7^{\circ} 15^{\prime} 18^{\prime \prime}$ 'de latitude Sul, 35'52'28', de longitude Oeste e altitude média de $550 \mathrm{~m}$.

Utilizou-se o delineamento estatístico em blocos casualizados, em esquema fatorial $4 \times 4$, sendo quatro níveis de salinidade da água de irrigação CEa: $(1,7 ; 3,4 ; 5,1$ e $6,8 \mathrm{dS}$ $\left.\mathrm{m}^{-1}\right)$ e quatro doses de matéria orgânica - MO $(0 ; 2,5 ; 3,5$ e $4,5 \%$ em base do volume de solo), combinados, os fatores resultaram em 16 tratamentos, com três repetições e uma planta por parcela, totalizando 48 plantas.

As plantas foram cultivadas em recipientes plásticos com aproximadamente $20 \mathrm{~L}$ de capacidade, sendo perfurados na base para introdução de drenos, acoplado a um recipiente para coleta da água de drenagem visando permitir o acompanhamento do volume drenado e o consumo de água pela cultura. No preenchimento, os vasos receberam uma camada de $250 \mathrm{~g}$ de brita a qual cobria a base do lisímetro e $22 \mathrm{~kg}$ de um Neossolo Regolítico Eutrófico de textura francoarenosa, não salino e não sódico, proveniente do município de Esperança, Paraíba, coletado na profundidade de 0-30 cm (horizonte A), cujas características químicas e físico-hídricas estão apresentadas na Tabela 1 .

Tabela 1. Características físicas e químicas do solo utilizado no experimento na Universidade Federal de Campina Grande, Campina Grande, Paraíba

\begin{tabular}{|c|c|c|c|c|c|c|c|c|}
\hline \multicolumn{9}{|c|}{ Características químicas } \\
\hline \multirow[t]{2}{*}{$\mathrm{pH}_{\mathrm{ps}}$} & \multirow{2}{*}{$\begin{array}{c}\text { M.O } \\
\text { dag kg-1 }\end{array}$} & \multirow{2}{*}{$\begin{array}{c}\mathrm{P} \\
\left(\mathrm{mg} \mathrm{kg}^{-1}\right)\end{array}$} & $\mathrm{K}^{+}$ & $\mathrm{Na}^{+}$ & $\mathrm{Ca}^{2+}$ & $\mathrm{Mg}^{2+}$ & $\mathrm{Al}^{3+}$ & $\mathrm{H}^{+}$ \\
\hline & & & \multicolumn{6}{|c|}{ 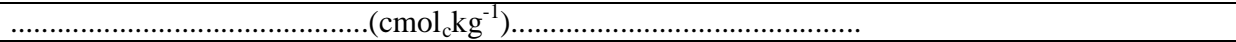 } \\
\hline 5,63 & 1,83 & 18,2 & 0,21 & 0,17 & 3,49 & 2,99 & 0,00 & 5,81 \\
\hline \multicolumn{9}{|c|}{ Características físico-hídricas } \\
\hline \multicolumn{3}{|c|}{ Fração granulométrica $\left(\mathrm{g} \mathrm{kg}^{-1}\right)$} & \multirow{2}{*}{$\begin{array}{l}\text { Classe } \\
\text { textural }\end{array}$} & \multicolumn{2}{|c|}{ Umidade $(\mathrm{kPa})$} & \multirow[t]{2}{*}{$\mathrm{AD}$} & \multirow{2}{*}{$\begin{array}{l}\text { Porosidade total } \\
\qquad \mathrm{m}^{3} \mathrm{~m}^{-3}\end{array}$} & \multirow{2}{*}{$\begin{array}{l}\text { Densidade } \\
\left(\mathrm{kg} \mathrm{dm}^{-3}\right)\end{array}$} \\
\hline Areia & Silte & Argila & & $\begin{array}{l}33,42 \\
\ldots \ldots \ldots \ldots . . .\end{array}$ & $\begin{array}{l}1519,5 \\
\text { dag } \mathrm{kg}^{-1}\end{array}$ & & & \\
\hline 572,3 & 100,8 & 326,9 & FA & 12,68 & 4,98 & 7,70 & 0,57 & 1,31 \\
\hline
\end{tabular}

$\mathrm{pH}_{\mathrm{PS}}$ - pH da pasta de saturação; M.O - Matéria orgânica: Digestão Úmida Walkley-Black; $\mathrm{Ca}^{2+}$ e $\mathrm{Mg}^{2+}$ extraídos com KCl 1 mol L ${ }^{-1}$ pH 7,0; Na e K ${ }^{+}$extraídos utilizando-se $\mathrm{NH}_{4} \mathrm{OAc} 1 \mathrm{~mol} \mathrm{~L}^{-1} \mathrm{pH} 7,0 ; \mathrm{FA}$ - Franco Argiloso; AD - Água disponível

Os distintos níveis de esterco bovino foram curtidos e adicionados em fundação, cujas quantidades foram determinadas considerando o teor de matéria orgânica no esterco igual a $45 \%$. A adubação de cobertura foi realizada com um formulado a base de nitrogênio $(\mathrm{N})$, fósforo $(\mathrm{P})$ e potássio $(\mathrm{K})$, conforme recomendação de adubação para ensaios em vasos contida em Novais et al. (1991), aplicandose as quantidades de 100,300 e $150 \mathrm{mg} \mathrm{kg}^{-1}$ de solo de $\mathrm{N}$, $\mathrm{P}_{2} \mathrm{O}_{5}$ e $\mathrm{K}_{2} \mathrm{O}$, respectivamente, nas formas de ureia, fosfato monoamônio e cloreto de potássio, sendo parcelada em duas aplicações em cobertura, via água de irrigação, aos 22 e 38 dias após a semeadura (DAS). Os vasos foram dispostos em fileiras simples espaçadas de $1 \mathrm{~m}$ e $0,6 \mathrm{~m}$ entre plantas na fileira.

As diferentes águas salinizadas foram preparadas utilizando-se relação empírica entre concentração de sais e CE sugerida por Richards (1954) $\left(10 * \mathrm{mmol}_{\mathrm{c}} \mathrm{L}^{-1}=1 \mathrm{dS} \mathrm{m}^{-1}\right)$ Com a umidade do solo elevada a nível correspondente ao da capacidade de campo com água dos distintos níveis salinos, realizou-se a semeadura colocando-se oito sementes por lisímetro a $1,5 \mathrm{~cm}$ de profundidade e distribuídas de forma equidistante. Aos 20 dias após semeadura (DAS) realizou-se o primeiro desbaste, deixando-se apenas cinco plantas por vaso, as de melhor vigor. Aos 26 e 30 DAS foram realizados novos desbastes, onde se eliminou em cada recipiente, duas plantas.

Após a semeadura, as irrigações foram realizadas diariamente, às 17 horas, aplicando-se, em cada recipiente, o volume de água correspondente à demanda da planta submetida ao tratamento. $\mathrm{O}$ volume aplicado em cada evento de irrigação foi estimado por meio de balanço de água, tomando-se como base a diferença entre volume aplicado e volume drenado, acrescido de $10 \%$ de fração de lixiviação.

Para o controle fitossanitário foram realizadas pulverizações utilizando o inseticida Dimetoato na concentração de $1,5 \mathrm{~mL} \mathrm{~L}^{-1}$ para controle de mosca branca de 
acordo com recomendação do fabricante. As pulverizações eram realizadas às 17 horas, como forma de amenizar a ocorrência de morte de insetos polinizadores.

Avaliaram-se os efeitos dos distintos tratamentos no período compreendido entre o crescimento e a produção do algodoeiro cv. BRS Jady a partir das variáveis, área foliar (AF), diâmetro do caulinar (DC) (mm), altura de planta (AP) $(\mathrm{cm})$, massa de algodão em pluma (MAP), massa total de sementes (MTS) e rendimento de fibra de algodoeiro (RFA) aos 114 dias após a semeadura (DAS).

A AP foi mensurada medindo-se a distância entre o colo e o ponto de inserção da folha mais nova; o DC foi determinado com um paquímetro digital, verificando-se, o colo da planta, a $5 \mathrm{~cm}$ acima do nível do solo. A determinação do número de folhas foi feita por contagem simples, considerando as que estavam com o limbo foliar totalmente aberto. Na estimativa da área foliar da planta (AF), foram tomadas medidas do comprimento da nervura principal de cada folha $(\mathrm{cm})$, considerando apenas as folhas com comprimento mínimo de $1,5 \mathrm{~cm}$ e com no mínimo $50 \%$ de sua área fotossinteticamente ativa. A área foliar total foi obtida de acordo com a metodologia de Grimes et al. (1969), a partir da Eq.1

$$
\mathrm{Y}=\sum 0,4322 \mathrm{x}^{2,3002}
$$

(Eq. 1)

Em que: $\mathrm{Y}=$ área foliar por folha $\left.\mathrm{cm}^{2}\right) ; \mathrm{x}=$ comprimento da nervura principal do algodoeiro.

Os capulhos foram colhidos por planta, à medida que atingiam o ponto de colheita, sendo quantificada a massa de algodão em sem caroço em balança de precisão de $0,001 \mathrm{~g}$.

Os dados obtidos foram submetidos à análise de variância pelo teste ' $F$ '. Nos casos de significância foram realizados estudos de regressão polinomial linear e quadrática, utilizando o software estatístico SISVAR versão 5.3 (FERREIRA, 2011).

Figura 1. Área foliar (AF), em função da salinidade da água de irrigação - CEa (A) e doses de matéria orgânica (B), altura de planta (AP) em função da salinidade da água de irrigação - CEa (C) e doses de matéria orgânica (D), do algodoeiro cv. BRS Jady aos 114 dias após semeadura (DAS).
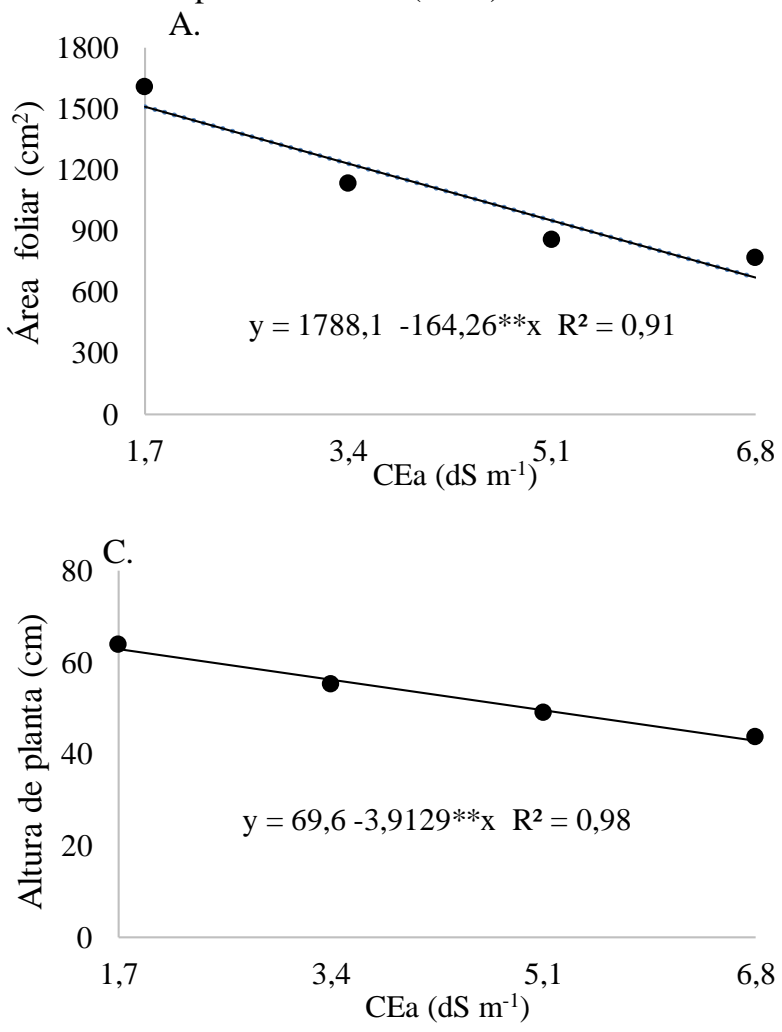

\section{RESULTADOS E DISCUSSÃO}

Conforme o resultado da análise variância houve efeito significativo da salinidade da água de irrigação e das doses de matéria orgânica sobre a altura de planta, área foliar e número de folhas. Observa-se efeito significativo $(p<0,01)$ da interação entre as salinidades da água e doses de matéria orgânica, sobre diâmetro do caule e fitomassa seca total aos 114 DAS.

$\mathrm{O}$ aumento da $\mathrm{CEa}$ afetou de forma negativa as variáveis área foliar e altura de planta (Figura 1A e C) respectivamente. De acordo com as equações de regressão percebe-se declínio na AF e AP respectivamente, de 9,18 e $5,62 \%$ por aumento unitário da $\mathrm{CEa}$, proporcional a uma diminuição nestas variáveis de $837,72 \mathrm{~cm}^{2}$ (55,52\%) e 19,95 $\mathrm{cm}(31,69 \%)$ na AF e AP das plantas irrigadas com água de $6,8 \mathrm{dS} \mathrm{m}^{-1}$ quando comparado com o menor nível salino $(1,7$

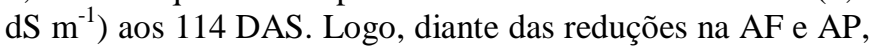
constata-se comportamento de sensibilidade das plantas de mecanismo para reduzir a perda de água ou resposta a deficiência hídrica, induzida pelo efeito osmótico, pode provoca alterações morfológicas e anatômicas nas plantas a ponto de ter prejudicado a absorção de água e a taxa de transpiração (SILVA et al., 2008).

Conforme a equação de regressão para área foliar do algodoeiro cv. BRS Jady (Figura 1B), observa-se com o aumento das doses de matéria orgânica fornecem incremento de $22,44 \%$ (AF) por aumento unitário da MO, ou seja, as plantas de algodoeiro quando cultivadas em solo com dose de 4,5\% de MO apresentaram aumento na AF de 692,64 $\mathrm{cm}^{2}$ quando comparada com as plantas que não receberam matéria orgânica $(0,0 \%)$. algodoeiro ao aumento da salinidade da água como
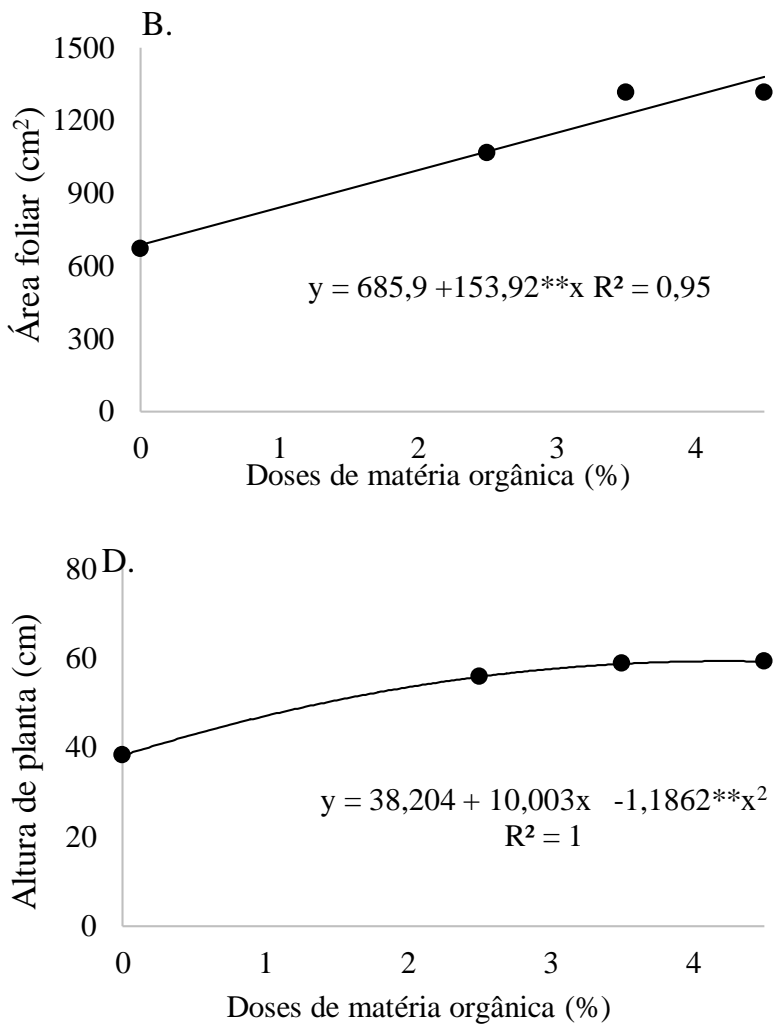
Para a variável AP aos 114 DAS (Figura 1D) constata-se que o incremento da adubação orgânica promoveu efeito quadrático sobre a altura de plantas do algodoeiro cv. BRS Jady, havendo aumento na AP até a adubação de MO de 4,2\% $(59,29 \mathrm{~cm})$, a partir desta dose de matéria orgânica, ocorreram reduções. $\mathrm{O}$ aumento destas variáveis pode está associada aos benefícios que a MO proporciona ao solo do ponto de vista físico e químico fornecendo condições para a propagação de microrganismos benéficos ao solo e as plantas refletindo em condições favoráveis ao desenvolvimento dos vegetais (MESQUITA et al., 2012).

Segundo as equações de regressão apresentadas na Figura 2, nota-se que o diâmetro caulinar apresentou uma resposta quadrática para as plantas adubadas com as doses de $0 \%$ de MO, sendo obtido o valor máximo no DC de $5,75 \mathrm{~mm}$ ao se irrigar com condutividade elétrica da água de irrigação de 1,7 $\mathrm{dS} \mathrm{m}^{-1}$. Observa-se ainda conforme equações de regressão, que o uso das doses de 2,5; 3,5 e 4,5\% de MO causaram redução linear por aumento unitário de 2,84; 2,69 e 3,32\% sobre o diâmetro caulinar. As plantas submetidas a condutividade da água de irrigação de $6,8 \mathrm{dS} \mathrm{m}^{-1}$ sofreram decréscimos de 1,06;0,99 e 1,36 mm com a utilização das doses de 2,5; 3,5 e 4,5\% de MO quando comparadas com as plantas que receberam a menor salinidade $\left(1,7 \mathrm{dS} \mathrm{m}^{-1}\right)$. Esta redução no diâmetro em condições de estresse salino é uma resposta ao fechamento dos estômatos e redução na transpiração e, consequentemente, diminuição na absorção de água e nutrientes pelas plantas, resultando em menor crescimento (LIMA et al., 2015).

Figura 2. Diâmetro do caule (A) e fitomassa seca total (B) do algodoeiro cv. BRS Jady, em função da interação entre os níveis de CEa e doses de matéria orgânica, aos 114 dias após semeadura (DAS).
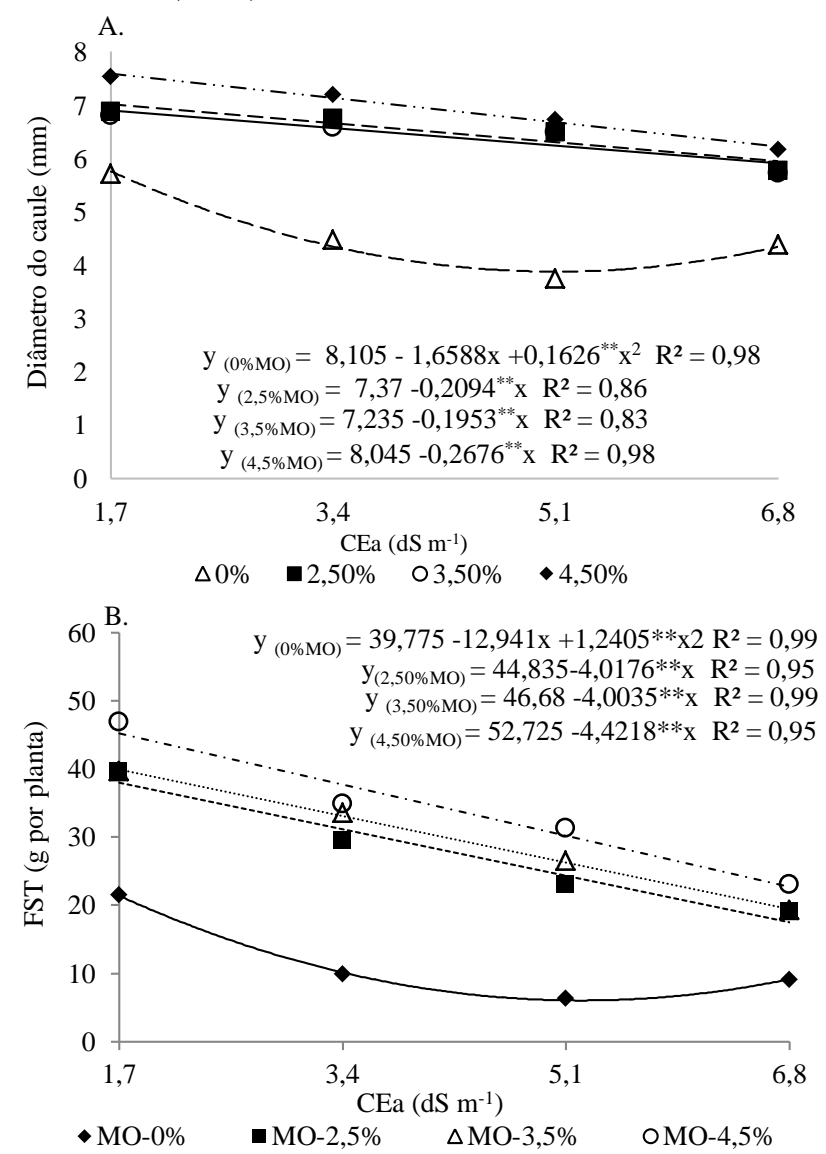

Aos 114 DAS, a FST foi afetada pela interação entre os fatores em estudo (NS x MO), e de acordo com equação de regressão (Figura $2 \mathrm{~B}$ ), em relação à dose de $0,0 \%$ de matéria orgânica, o modelo ao qual os dados se ajustaram melhor foi o quadrático, onde se notou que o valor máximo de 21,33 g foi encontrado na CEa de 1,7 $\mathrm{dS} \mathrm{m}{ }^{-1}$. Conforme regressões das demais doses de 2,5; 3,5 e 4,5\% de MO (Figura 2B), a FST foi afetada linearmente com diminuições de 53,90; 51,20 e $59,13 \%$, respectivamente, nas plantas irrigadas com água de maior salinidade $\left(6,8 \mathrm{dS} \mathrm{m^{-1 }}\right)$, em comparação àquelas irrigadas com água de menor nível salino $\left(1,7 \mathrm{dS} \mathrm{m}^{-1}\right)$. Os efluentes orgânicos incrementam a produção de solutos orgânicos e, também apresentam a capacidade de elevar a capacidade das plantas se ajustarem aos sais (GHOULAM et al., 2002).

Houve efeito significativo do fator salinidade da água de irrigação e doses de matéria orgânica sobre massa total de sementes do algodoeiro cv. BRS Jady. Para rendimento de fibra de algodoeiro observa-se efeito significativo apenas das doses de matéria orgânica. Em relação à interação entre os fatores (salinidade da água de irrigação e doses de matéria orgânica), foi observado efeito significativo para massa total de sementes.

A partir das equações de regressão (Figura 3), observa-se que massa de algodão em pluma apresentou uma resposta quadrática para as plantas submetidas a adubação com as doses de 0 e 4,5\% de MO, sendo obtido o máximo de produção em MAP de 9,70 e 21,82 g nas plantas irrigadas CEa de 1,7 dS $\mathrm{m}^{-1}$. Já a adubação com esterco bovino aplicado em fundação proporcionou redução na massa de algodão em pluma aos 114 DAS, entretanto a intensidade dos efeitos causados pela salinidade da água de irrigação esta interligada com a concentração dos sais presentes na água utilizada para irrigação (Figura 3). Nota-se pelas equações de regressão que as doses de $\mathrm{MO}$ de 2,5 e 3,5\% resultou na menor produção de MAP, quando utilizada a CEa de 6,8 dS $\mathrm{m}^{-1}$. Observa-se uma redução por aumento unitário da CEa de 9,78 e $9,93 \%$ respectivamente. Essa redução pode ser resultado da quantidade de nutrientes na composição do substrato, causando um eventual efeito depressivo ou consequência da maior retenção de umidade devido à maior quantidade de matéria orgânica com redução no teor de oxigênio (OLIVEIRA et al., 2013).

Figura 3. Massa de algodão em pluma do algodoeiro cv. BRS Jady, em função da interação entre os níveis de CEa e doses de matéria orgânica, aos 114 dias após semeadura (DAS).

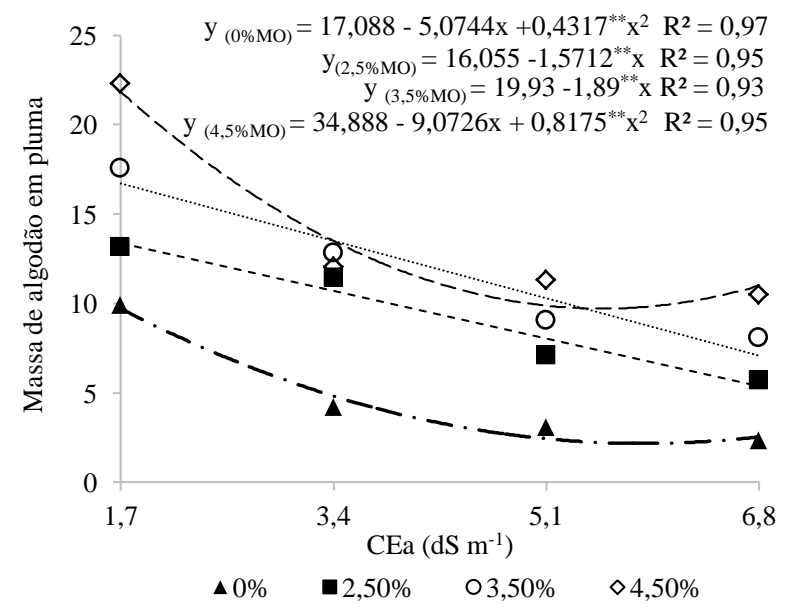


Verifica-se na Figura 4A que os dados referentes à massa total de sementes de algodão ajustaram-se ao modelo quadrático, sendo obtido o valor máximo de MTS (21,07 g) nas plantas que receberam água de condutividade elétrica de $1,7 \mathrm{dS} \mathrm{m}^{-1}$. Denota-se que aos 114 DAS, as plantas sob níveis mais elevados de salinidade da água, tiveram menor massa total de sementes em relação as que estavam sob menor nível salino. Fato que pode estar relacionado com ajustamento do potencial hídrico da cultura, sob condições de estresse salino (COELHO et al., 2014).

Figura 4. Massa de cem sementes do algodoeiro cv. BRS Jady, em função da salinidade da água de irrigação - CEa (A) e doses de matéria orgânica (B), e rendimento de fibra de algodoeiro (C), em função de doses de matéria orgânica, aos 114 dias após semeadura (DAS).
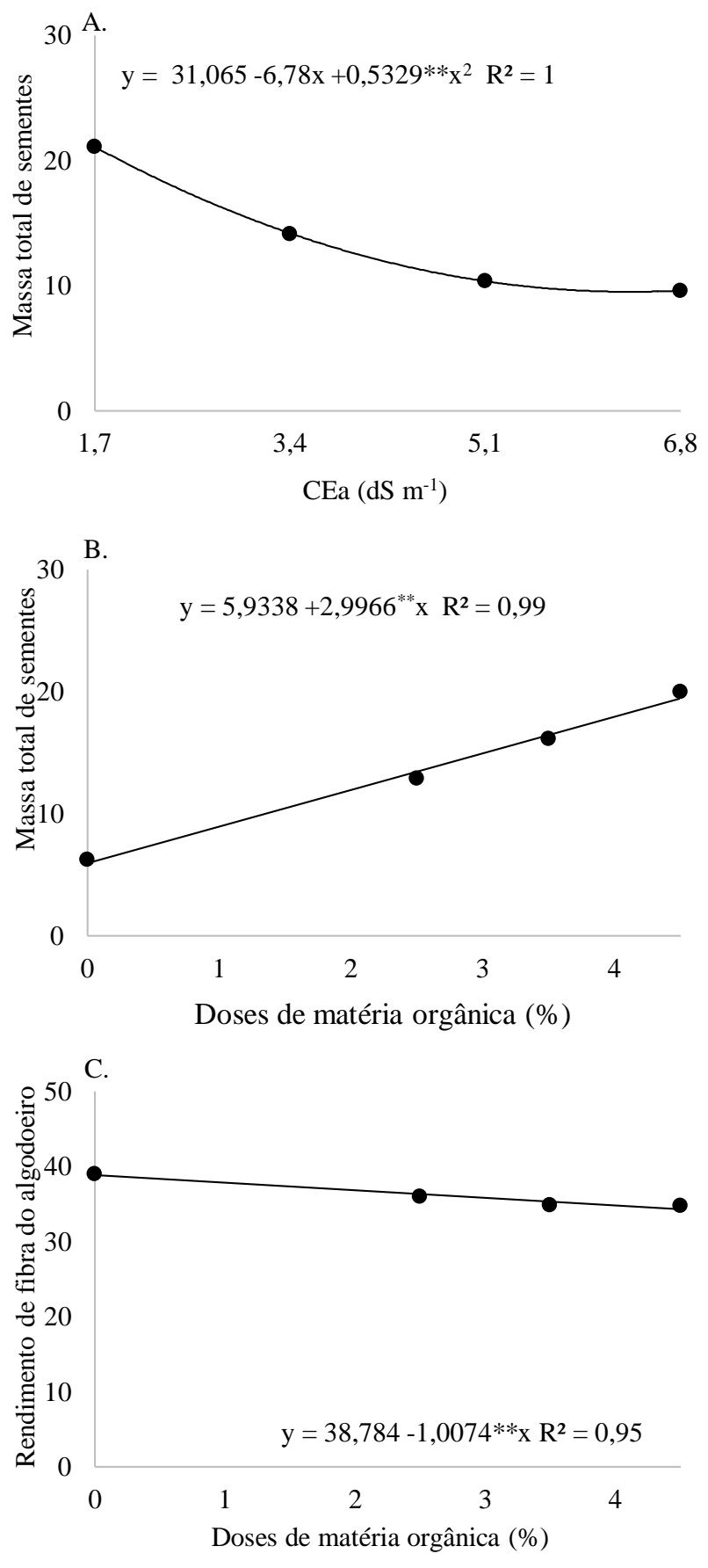

Revista Verde, v.12, n.1, p.79-84, 2017
$\mathrm{O}$ aumento da adubação orgânica afetou de forma positiva a massa total de sementes do algodoeiro cv. BRS Jady aos 114 dias após semeadura e de acordo com as equações de regressão (Figura 4B) percebe-se aumento na MTS, de $72,51(14,08 \mathrm{~g})$ das plantas adubadas com a dose de 4,5\% de MO quando comparado com a menor dose (0,0\% de MO). Entretanto para RAF (Figura 4C) o incremento na adubação orgânica proporcionou efeito linear decrescente de 2,59\% por aumento unitário da MO sobre a RAF aos 114 DAS. As plantas quando postas sobre a adubação orgânica de 4,5\% de MO sofreram reduções na RFA de $11,68 \%(3,70)$ em relação as plantas adubadas com $0,0 \%$ de $\mathrm{MO}$.

\section{CONCLUSÕES}

A irrigação com água salina de CE a partir $1,7 \mathrm{dS} \mathrm{m} \mathrm{m}^{-1}$ afeta negativamente o crescimento e a produção do algodoeiro cv. BRS Jady, provocando reduções no diâmetro de caule, altura de planta, área foliar, fitomassa seca total, massa de algodão em pluma, massa total de sementes e rendimento de fibra.

A adubação orgânica promove aumento na altura de plantas, área foliar e massa total de sementes do algodoeiro cv. BRS Jady.

Houve interação entre os fatores aguas salinas e doses de matéria orgânica para diâmetro caulinar, fitomassa seca total e massa de algodão em pluma, sendo os maiores valores obtidos na das doses de 3,5 e 4,5\% de matéria orgânica.

\section{REFERÊNCIAS}

CARDOSO, G. D.; AlveS, P. L. da C. A.; BELTRÃO, N. E. de M.;VALE, L. S. do. Períodos de interferência das plantas daninhas em algodoeiro de fibra colorida BRS Safira. Revista Ciência Agronômica, v. 41, n.3, p. 456-462, 2010.

COELHO, D. S. SIMÕES, W. L. MENDES, A. M. S. DANTAS, B. F. RODRIGUES, JOSÉ A. S. SOUZA, M. A. de. Germinação e crescimento inicial de variedades de sorgo forrageiro submetidas ao estresse salino. Revista Brasileira de Engenharia Agrícola e Ambiental. v.18, n.1, p.25-30, 2014.

DIAS, A. S.; NOBRE, R. G.; LIMA, G. S.; GHEYI, H. R.; PINHEIRO, F. W. A. Crescimento e produção de algodoeiro de fibra colorida cultivado em solo salino-sódico e adubação orgânica. Irriga, Botucatu, Edição Especial, p. 260-273. 2016. FERREIRA, D. F. Sisvar: A computer statistical analysis system. Revista Ciência e Agrotecnologia, Lavras, v. 35, n. 6, p. 1039-1042. 2011

GHOULAMET, C. Effects of salt stress on growth, inorganic ions and proline accumulation in relation to osmotic adjustment in five sugar beet cultivars. Environmental and Experimental Botany, v.47, n.1, p.39-50, 2002.

GRIMES, D. W.; CARTER, L. M. A linear rule for direct non destrutive leaf área measurements. Agronomy Journal, v.61, n.3, p 477-479, 1969.

LIMA, G. S. de; NOBRE, R. G.; GHEYI, H. R.; SOARES, L. A. dos A.; SILVA, A. O. da. Crescimento e componentes de produção da mamoneira sob estresse salino e adubação 
nitrogenada. Revista Engenharia Agrícola, v.34, n.5, p. 854866, 2014.

LiMA, L. A. OliveirA, F. de A. ALVES, R. de C. LINHARES, P. S. F. MEDEIROS, A.M. A. de. BEZERRA, F. M. S. Tolerância da berinjela à salinidade da água de irrigação. Revista Agroambiente, v.9, n.1, p.27-34, 2015.

MESQUiTA, E. F., CHAVES, L. H. G., FREITAS, B. V., SILVA, G. A., SOUSA, M. V. R. ANDRADE, R. Produção de mudas de mamoneira em função de substratos contendo esterco bovino e volumes de recipientes. Revista Brasileira de Ciências Agrárias, v.7, n.1, p.5865, 2012.

NEVES, A. L. R.; LACERDA, C. F. de; GUIMARÃES, F. V. A.; HERNANDEZ, F. F. F.; SILVA, F. B. da; PRISCO, J. T.; GHEYI, H. R. Acumulação de biomassa e extração de nutrientes por plantas de feijão-de-corda irrigado com água salina em diferentes estádios de desenvolvimento. Ciência Rural, v.39, n.3, p.758-765, 2009.

NOVAIS, R. F.; NEVES, J. C. L.; BARROS, N. F. Ensaio em ambiente controlado. In: Oliveira, A. J. (ed.) Métodos de pesquisa em fertilidade do solo. Brasília: Embrapa SEA, 1991. p.189-25.

OLIVEIRA, F. T. de.; HAFLE, O. M.; MENDONÇA, V.; MOREIRA, J. N.; MENDONÇA, L. F. REITAS DE M. Fontes e proporções de materiais orgânicos na germinação de sementes e crescimento de plantas jovens de goiabeira. Revista Brasileira Fruticultura, v. 35, n. 3, p. 866-874, 2013.

RICHARDS, L. A. Diagnosis and improvement of saline and alkali soils. Washington: U. S. Department of Agriculture, 1954. 160p. Agriculture Handbook, 60.

SILVA, S. M. ALVES, A. N. GHEYI, H. R. BELTRÃO, N. E. de M. SEVERINO, L. S. SOARES, F. A. L. Desenvolvimento e produção de duas cultivares de mamoneira sob estresse salino, Revista Brasileira de Engenharia Agrícola e Ambiental. v.12, n.4, p. 335-342, 2008 .

TAVARES FILHO, A. N.; BARROS, M. de F. C.; ROLIM, M. M.; SILVA, Ê. F. de F. Incorporação de gesso para correção da salinidade e sodicidade de solos salino sódicos. Revista Brasileira de Engenharia Agrícola e Ambiental, v. 16, n.3, 247-252, 2012. 